\title{
La evaluación participativa en la Nueva Gestión Pública
}

\author{
Antonio Trinidad Requena \\ Universidad de Granada \\ atrinida@ugr.es
}

Resumen: Todo proceso de evaluación tiene unos efectos, los explícitos son los que acaparan la atención de los evaluados y evaluadores, olvidándose de los efectos implíitos. Sin embargo, el autentico poder de la evaluación está en los efectos implíitos. Los implicado en la evaluación para evitar ser evaluado negativamente adaptaran su comportamiento personal y profesional a los parámetros que mide la evaluación, siendo uno de los efectos implíitos de toda evaluación; de esta manera al final se impondrá el modelo de intervención o gestión que subyace en toda evaluación, siendo la fuerza invisible de la evaluación, y en ocasiones utilizada para evitar conflictos dentro de la Administración pública, al permitir imponer un modelo de gestión que de otra manera no sería aceptado por los implicados. Atendiendo a tales efectos, la evaluación puede optar por otras perspectivas como la evaluación democrática que propone B. Macdonald (1991), al considerar la evaluación democrática como un servicio a la comunidad implicada en la política pública u organización, y que en este caso llamaremos evaluación participativa.

Palabras claves: evaluación democrática, negociación, efectos implícitos, efectos explícitos.

Abstract: Every evaluation process has some effects. The explicit ones will command the attention of the evaluators and those evaluated, while the implicit ones go unnoticed. However, the real power of evaluation lies in its implicit effects. Those being evaluated will adapt their personal and professional behavior to the parameters which the evaluation measures, which is one of the implicit effects of every evaluation. Thus, eventually, the model of intervention or management that underlies each evaluation is imposed, since it is the invisible force behind the review. On occasion, this is used to avoid conflict within public administration, since it permits the imposition of a model of management which otherwise would not be accepted by those involved. In response to such effects, evaluators may choose other perspectives, such as democratic evaluation which B. Macdonald (1991) proposes, since it is more a service to the community involved in the public policy or organization. In this case we will call it participatory evaluation.

Key words: democratic evaluation, negociation, implicit effects, explicit effects 


\section{Introducción: de la evaluación impositiva a la evaluación participativa}

Como es sabido, Stufflebeam y Shinkfield (1987) señalan cinco períodos básicos en el desarrollo de la evaluación en Estados Unidos: el período pretyleriano; la época tyleriana; la época de la «inocencia»; la época del realismo, y la época del profesionalismo, surgida en la década de 1970. La época del profesionalismo se caracteriza por el desarrollo y la importancia que adquiere la teoría, si nos atenemos a la cantidad de publicaciones - tanto revistas como libros - aparecidas en los años setenta, así como al interés por la elaboración de programas por parte de las universidades para graduarse en evaluación. Otras aportaciones importantes de esta época son la metaevaluación - la evaluación de las evaluaciones-, considerada como un medio para asegurar y comprobar la calidad de las evaluaciones, y las normas para juzgar y guiar las evaluaciones de los programas.

Ahora bien, en esta etapa, sobre todo, emergen algunos de los dilemas del campo de la evaluación vigentes hasta hoy. Uno de ellos es quién debe realizar la evaluación. La mayoría de los teóricos estadounidenses, según H. Simons (1999), consideran que la evaluación debe correr a cargo de quien tenga los mayores conocimientos y destrezas y, ante todo, de quienes sean lo menos tendenciosos (subjetivos); por ello abogan por el especialista de la evaluación, pues, al contemplar la evaluación principalmente como metodología, no tratan directamente la dimensión política ni tienen en cuenta el contexto político en que se llevan a cabo las evaluaciones. En cambio, la dimensión y el contexto políticos son cuestiones clave que se plantean en el viejo continente de la mano de los teóricos de la escuela naturalista británica, que consideran que son los especialistas de cada campo los que deben llevar a cabo la evaluación. Desde este último punto de vista, la función reservada al evaluador es ayudar a los profesionales a adquirir las técnicas adecuadas para convertirse en coevaluadores.

El concepto de evaluación naturalista, para Helen Simons (1999), llegó a ser la expresión genérica utilizada para describir muchos de los enfoques alternativos de la evaluación; esta expresión adquirió relieve en los años sesenta como reacción a las formas más tradicionales de evaluación, que se mostraron insuficientes para comprender la complejidad de los fenómenos sociales. Entre estos enfoques alternativos se encuentran: la evaluación holística, la evaluación democrática (McDonald), la evaluación iluminadora (Hamilton-Parlett), la evaluación responsiva (Stake), la evaluación transaccional (Rippey, 1973) y la evaluación como crítica literaria (Nelly, 1994), entre otros. Todos estos enfoques surgen del reconocimiento de las insuficiencias del modelo experimental de investigación para evaluar programas que se desarrollan en la acción y que producen efectos diferentes en contextos distintos. En definitiva, son modelos de 
evaluación pluralista que tienen en cuenta las posturas de valor de múltiples destinatarios, con premisas políticas subyacentes que contemplan los efectos implícitos de la evaluación.

Uno de los artículos que tuvo una influencia fundamental en la teoría y la práctica de la evaluación en el Reino Unido fue «Evaluation and the control of education» (McDonald), que se ocupaba directamente de la dimensión política y planteaba una clasificación política de la evaluación en términos de tipos ideales: evaluación burocrática, evaluación autocrática y evaluación democrática. Partiendo de esta idea analizaremos el concepto de evaluación como imposición de un modelo de gestión a través de los efectos implícitos de la evaluación, para llegar a la evaluación como construcción de un modelo participativo de gestión.

Ahora bien, desde esa profesionalización de la evaluación, al acercarnos al concepto de evaluación, nos encontramos con multitud de aproximaciones al término. Ello se debe, en la mayoría de los casos, a que hay especialistas que centran su atención en la consecución de los objetivos o resultados; otros, por el contrario, se centran en el funcionamiento directo del programa, y, por último, están aquellos que se centran en la evaluación antes de la implementación del programa. Al revisar la bibliografía especializada nos encontramos con autores que enfatizan en su definición el objetivo de la evaluación, respondiendo a la pregunta ¿para qué evaluar? En este caso la evaluación es un proceso de reflexión sistemática sobre la actividad de un programa público que contribuye a comprender, con mayor profundidad, aquello que se está realizando y sus resultados, $y$, por otra parte, a tomar decisiones que faciliten la mejora a partir de los patrones de referencia de la evaluación.

Para otros autores, además de la finalidad, la utilidad de la evaluación es esencial. Así lo reflejan en sus definiciones, al constatar que la evaluación es un proceso que genera y comunica comprensión sobre la práctica para que sea útil. Entendiendo por «utilidad» la ampliación de la calidad de todos y cada uno de los participantes para utilizar la práctica como un recurso crítico para buscar mejoras, sin cuestionar el sentido y significado del concepto de calidad. Otros autores ven su utilidad en la reflexión sobre la práctica, al entender la evaluación como la puesta en marcha de un proceso que exige, por parte de quienes lo inician, la voluntad de reflexionar sobre la práctica con el ánimo profesional de aprender de ella de forma constante. Esta reflexión toma como modelo ideal el implantado en la evaluación.

El proceso de la evaluación es otra de las cuestiones que los autores suelen destacar en la definición, cuya centralidad la ocupa la metodología. Éste es el caso de Quinn Patton (1991), que define la evaluación como la colección sistemática de información acerca de actividades, características y resultados de un programa, para hacer un estudio sobre éste, mejorar su efectividad y/o proveer información acerca de su futuro. 
En otros casos, la definición resalta uno de los elementos distintivos de toda evaluación: el juicio de valor. Así, la evaluación es la emisión de un juicio sobre el valor de algo proyectado o realizado por algún individuo o grupo, y presupone un proceso de recogida de información sistemática y relevante que garantice la «calidad» del juicio formulado. En este sentido, hay dos elementos indispensables: una información lo más objetiva, válida y fiable posible, cuantitativa y/o cualitativa, y unos criterios racionales, acordes con la concepción que se tenga de la evaluación, que permitan interpretar la información y hacer el juicio de valor.

En caso de centrar la atención sólo en el final del proceso o en los resultados de la intervención pública, la evaluación estaría enmarcada en una visión restrictiva, olvidándose del diseño del programa y de la implementación. Desde esta perspectiva restrictiva, la evaluación de programas sociales supone la aplicación sistemática de métodos cualificados de las ciencias sociales con la intención de medir los impactos socioeconómicos de las intervenciones causadas por un conjunto de medidas aplicadas en un tiempo determinado.

Por el contrario, atendiendo al conjunto del proceso de la intervención social, la evaluación de programas sociales sería la aplicación sistemática de métodos cualificados de las ciencias sociales con la intención de conocer y juzgar el diseño, los procesos, los resultados $y$ los efectos de las intervenciones causadas por un conjunto de medidas aplicadas en un tiempo y contexto determinados.

En resumen, bajo las premisas de la profesionalización de la evaluación y según las distintas definiciones, la evaluación es algo que se aproxima al enjuiciamiento sistemático de la valía o el mérito de una intervención pública. Un estudio sistemático planificado, dirigido y realizado para mejorar la intervención o ayudar a los implicados a juzgar y/o perfeccionar el valor y/o el mérito del programa. En definitiva, el concepto de evaluación tiende a dar respuesta a las preguntas: ¿para qué evaluamos? y ¿cómo haremos la evaluación? Responder a estas dos cuestiones implica centrar la atención en los efectos explícitos de la evaluación y optar por un tipo u otro de evaluación, olvidándose de otras cuestiones fundamentales dentro del amplio ámbito de la evaluación, como por ejemplo los efectos implícitos.

La evaluación, además, trasciende las cuestiones metodológicas. Ésta es una de las características que la diferencian de la investigación aplicada, sobre todo por sus efectos sobre las personas y sobre la manera de entender la intervención social y la gestión de esa intervención; es más, sobre los principios políticos que subyacen tras esa intervención social. Por una parte, las personas afectadas pueden modificar o alterar su comportamiento si quieren, sobre todo cuando son evaluadas. Es un hecho, como señala Scrive, que nadie quiere ser evaluado: los profesores no quieren que los evalúen 
los alumnos, ni los alumnos quieren que los evalúen los profesores; de igual manera, tampoco quieren ser evaluados los trabajadores, los profesionales ni los políticos.

Pero, además, como es sabido, los resultados pueden influir en muchas personas; los afectados pueden ser muchos, sobre todo cuando se emite un juicio de valor sobre el trabajo que realizan. Así, para evitar ser evaluados negativamente, los implicados adaptarán su comportamiento personal y profesional a los parámetros que mide la evaluación, siendo uno de los efectos implícitos de toda evaluación; de esta manera, al final se impondrá el modelo de intervención o gestión que subyace en toda evaluación, siendo la fuerza invisible de la evaluación, que en ocasiones es utilizada para evitar conflictos dentro de las organizaciones al permitir imponer un modelo de gestión que de otra manera no sería aceptado por los implicados.

Atendiendo a tales efectos implícitos, la evaluación puede optar por otras perspectivas, como es el caso de la evaluación democrática que propone B. McDonald (1991) al considerar la evaluación democrática como un servicio a la comunidad implicada en el programa o la organización, y que en este caso llamaremos evaluación participativa. Basándonos en tales principios, la evaluación se define como aquella en la que, tanto los métodos aplicados como la información generada en el proceso evaluador, son abiertos y se discuten y reelaboran entre los diferentes grupos de interés, formales o no, que configuran el programa, la organización o la política.

\section{El porqué de la evaluación participativa: los efectos implícitos de la evaluación}

La actividad evaluadora va formando parte, con presencia muy desigual, de la vida de las organizaciones prestadoras de servicios sociales, tanto públicas como privadas, con repercusiones diferentes y objetivos muy distintos. Los objetivos que conseguir, al evaluar un programa público de intervención social, pueden variar según el grupo o la persona de quien procede la iniciativa de la evaluación y de sus pretensiones más inmediatas. Conviene recordar que evaluar implica hacer un juicio de valor que debe hacerse basándonos en la información proporcionada por la propia evaluación; cuestión que debe tenerse clara como profesionales de la evaluación, pues, de lo contrario, se puede ser víctima de la complejidad de intereses políticos, sociales o económicos que suelen llevar implícitos la mayoría de los programas de intervención social. Así, por ejemplo, los responsables de tomar decisiones necesitan una evaluación que les permita aclarar cuestiones comoः ¿debería continuar el programa o interrumpirse?, ¿deberían asignarse más fondos a este programa?, ¿cuál es el grado de eficacia general del programa? Los directores del programa, los patrocinadores, los beneficiarios, los diseñadores, los com- 
petidores del programa, etc., esperan de la evaluación objetivos muy diferentes. Por ello es necesario conocer tanto los objetivos implícitos como los explícitos de todos los implicados en el conjunto de intereses del campo de acción del programa. En este mismo sentido se pronuncia Subirats (1998) cuando dice que «la pluralidad de intereses puede repercutir de diversa manera en el proceso de evaluación. Ante todo, por la dificultad de definir la mejor perspectiva desde la que abordar la evaluación».

Por existir esta amalgama de intereses, los profesionales de la evaluación deben señalar con precisión los objetivos que se pretenden conseguir con la evaluación del programa. Conviene diferenciar entre objetivos generales y específicos. Entre los primeros destaca el conocimiento de los procesos de aplicación y de los resultados de la intervención pública en la sociedad. De los específicos, dependiendo de la finalidad de la evaluación, señalaremos: 1) proporcionar diferentes propuestas en la toma de decisiones; 2) conocer la opinión de los usuarios de los servicios; 3 ) conocer el grado en que el programa se aplica tal como fue previsto; 4) conocer los efectos colaterales o no esperados y derivados de la aplicación del programa. Uno de estos efectos puede ser la resolución de conflictos dentro de la organización, por cuanto la evaluación incorpora nueva información al sistema y amplía las posibilidades de negociación y sus efectos de reducción de la autocomplacencia; 5) mejorar sus prácticas y procedimientos; 6) añadir o desechar estrategias y técnicas específicas al programa, y 7) conocer su eficiencia/ eficacia.

Ahora bien, en función de los objetivos a perseguir, toda evaluación tiene unos efectos, bien explícitos — previstos - o bien implícitos, sobre la actividad de los implicados en la evaluación. Al señalar tanto los objetivos generales como los específicos de cualquier tipo de evaluación, estamos haciendo, a la vez, explícitos los efectos previstos de la evaluación, como: el legitimar una decisión; el intentar aumentar la eficiencia/ eficacia del programa; el querer aumentar el prestigio de la organización o el personal afectados por la evaluación; el tomar conciencia del quehacer diario de todos los implicados, o, simplemente, el crear una cultura evaluativa. Junto a los efectos previstos se encuentran los no previstos o colaterales, entre los que podemos destacar: el aumento de la autoestima de los implicados; el aumento de la competitividad/recelos/envidias entre los compañeros (el clima laboral puede modificarse); el aumento de la demanda de nuevos programas; la asignación de una distinción al programa como sinónimo de calidad, y, entre los efectos negativos, el aumento del rechazo a la evaluación.

En cuanto a los efectos implícitos, en pocas ocasiones se hace referencia a ellos. Podemos destacar:

a) Impone un modelo de proceder o gestión invisible, bien en el marco general o bien en el patrón de referencia utilizado en el juicio de valor, constituyendo la fuerza invisible de la evaluación. 
b) Legitima el cuestionamiento de la profesionalidad de los implicados.

c) Respecto a su utilización política, legitima los intereses corporativos y de poder.

De ninguno de los tres efectos se suele hacer mención en la literatura especializada, tampoco por los que toman la decisión de evaluar, como es de esperar, sobre todo por su efecto impositivo de un modelo de intervención social o de gestión implícito en toda evaluación. Toda evaluación toma como base un modelo ideal de gestión en el sentido weberiano. Esto hace que los profesionales que trabajan en estas organizaciones deban ir adaptando su práctica profesional, en ocasiones premeditadamente y en otras de forma inconsciente, a las prácticas que se consideran positivas dentro de los indicadores de medida utilizados en la evaluación. En otras palabras, el profesional de los servicios públicos, como cualquier profesional, quiere ser evaluado positivamente, por lo que irá adaptando su quehacer diario al modelo ideal que será el sancionado como positivo a la hora de hacer el juicio de valor que implica toda evaluación. Como bien señala House (1994), podemos entender la evaluación como persuasión. La evaluación persuade de la conveniencia de algo, lo que constituye un curso de acción: «la evaluación aspira a persuadir a un público concreto del valor de algo o de que ese algo es lo que interesa, apelando a la razón y la comprensión del público». Incluso señala que, a mayor rechazo explícito a la evaluación, mayor acción implícita al cambio, al cobrar especial relieve el contexto social y psicológico.

Lo más parecido al efecto de la imposición de un modelo de gestión es el conocido efecto Hawthorne, que se produce cuando un sujeto, al darse cuenta de que es motivo de evaluación, modifica su comportamiento habitual. Un ejemplo de este efecto puede darse al utilizar la observación científica en la evaluación. Un profesional o un grupo de usuarios pueden modificar su comportamiento ante la presencia de un evaluador externo. El efecto John Henry, por su parte, que merece igualmente mención, consiste en producir una fuerte reacción competitiva.

Las preguntas para determinar el grado de imposición de un modelo de gestión son: ¿cómo se han seleccionado tales indicadores?, ¿qué proceso se ha seguido?, ¿a qué intereses responde ese modelo de gestión?

Por estas y otras preguntas, en general nadie quiere ser evaluado. El efecto de imposición y, con ello, de un cierto modelo de gestión otorga a la evaluación una gran fuerza invisible de transformación. En este sentido, cualquier responsable de una organización prestadora de servicios puede recurrir a la evaluación para imponer un modelo de gestión ante la negativa de los profesionales a aceptar ese nuevo modelo, con lo que así se evitan conflictos y rechazos. No sólo la imposición de la evaluación es motivo de rechazo. Esta actitud, en general, está relacionada en nuestro país con la escasa implantación de esta actividad y, sobre todo, con el criterio de considerar la evaluación 
sólo en su aspecto sancionador y de control. Sin embargo, en otros países europeos y, sobre todo, en los Estados Unidos, es una actividad usual que se ha extendido a lo largo de las últimas décadas. Esta práctica está ligada a una concepción más amplia sobre el contenido evaluador. En nuestra sociedad, la evaluación está asociada culturalmente al control y la sanción, y en raras ocasiones se ve como práctica de mejora.

En diferentes ámbitos laborales, la mayoría de los implicados no quieren ser evaluados. Por ello, cuando se inicia un proceso de evaluación los argumentos para oponerse son múltiples y de muy diferente calado. Entre las alegaciones que se suelen hacer destacan:

1. Que se hagan públicos los criterios de evaluación.

2. Que se definan los objetivos de la evaluación.

3. Que se especifiquen las repercusiones de la evaluación.

4. Que se clarifiquen los encargados de llevar a cabo la evaluación.

5. Que la evaluación no sirve para nada, etc.

Ante tal rechazo, varios autores se han pronunciado sobre la dificultad de la evaluación. Sancho Gil (1990), McDonald y Roe (1991), Bater (1988) y Trinidad (1995, 2007), entre otros, abordan el tema desde diferentes puntos de vista. McDonald y Roe constatan, en primer lugar, la idea sugerida por algunos de los implicados de no efectuar una evaluación sistemática, aduciendo como razones el temor a que los evaluadores no sean competentes o considerados, o a que utilicen un criterio equivocado, o a que las revisiones cuesten dinero y no sirvan para ningún propósito útil e, incluso, puedan hacer daño. Temores posibles de hacerse realidad si la evaluación no está bien pensada y planificada, por lo que, para evitar tales problemas, se sugiere responder y hacer explícitos los siguientes interrogantes: ¿cuál es el propósito de la evaluación?, ¿cuáles son las cuestiones a revisar?, ¿cómo se debe organizar?, ¿quién debe efectuar la evaluación?, ¿qué información se precisa de quién y cómo?, ¿cómo se debe procesar la información?, ¿qué tipo de informes se deben efectuar y para quién?, y, por último, ¿Cómo asegurar que las propuestas se lleven a cabo?

Otra cuestión de enorme importancia es el tema de la imparcialidad de la evaluación. En este mismo sentido se pronuncia Bater (1988) al afirmar que en realidad «la evaluación rara vez es neutral, siendo de hecho más probable que sea problemática, ya que, invariablemente, implica intereses, aspiraciones y actividades de uno o más grupos de personas. La verdadera decisión para efectuar una evaluación supone que lo que se coloca bajo escrutinio pueda ser dirigido de formas alternativas que podrían ser más beneficiosas, o que los recursos dedicados a la actividad podrían ser aplicados mejor en otra parte, y así sucesivamente». 
Sea por temor, hastío funcionarial, ignorancia o convicción de que tal trabajo no es útil para nada, la evaluación es bastante impopular entre sus actores y, en todo caso, muy raramente ejercitada. Ante tal cúmulo de hechos, consideramos necesario realizar una fase previa a la implantación de cualquier proceso de evaluación institucional, durante la cual lo importante es crear un clima favorable hacia ésta y sensibilizar a cada uno de los implicados y servicios de la Administración de la necesidad de la evaluación y de sus ventajas, dándoles a conocer las competencias respecto a las cuales va a ser evaluada su actividad y estableciéndose los objetivos que, en cada caso, van a ser utilizados como criterios de evaluación; en definitiva, hacer entender que la evaluación va precedida de un proceso de negociación.

\section{Las nuevas lógicas de la evaluaciónł la negociación como lema}

Cuando se parte de un planteamiento impositivo en la evaluación, la lógica de la intervención social más común es la basada en: 1) las necesidades de la población; 2) la planificación de un nuevo plan de intervención; 3) la aplicación de ese plan de intervención, y 4) la evaluación. En otras palabras, cuando se decide intervenir en un determinado contexto social, esa intervención debe basarse en los problemas y las necesidades reales de esa ciudadanía. A partir del estudio de las necesidades, elaboramos un nuevo plan de intervención que debe constar de unos objetivos, unos recursos, unas actividades y, al final, un producto. Este producto son los resultados, y los efectos de esos resultados. Esta lógica de la intervención social implica conocer los efectos sobre las necesidades/ problemas, o lo que es lo mismo, si con los efectos producidos por las nuevas mejoras se han cubierto las necesidades y si esas necesidades, en el cambio esencial, dependen de la nueva intervención. En esta lógica, la evaluación queda relegada al final de un proceso lineal de intervención, que por sus efectos implícitos terminará imponiendo el modelo de intervención social subyacente en el modelo de evaluación. De forma gráfica queda reflejada en la figura 1 lo que denominamos lógica lineal de intervención.

Figura 1. La lógica lineal de la intervención socialı la evaluación como fin de un proceso

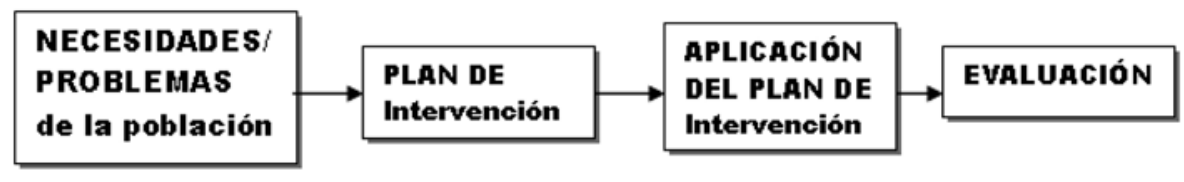


Dentro de toda esta lógica de la intervención social, la evaluación forma parte del final del proceso y se centra en los resultados de la intervención. La evaluación es entendida en sentido restrictivo y, además, puede ser utilizada como mecanismo de imposición de una manera concreta de proceder, sin el consentimiento de los implicados en el diseño y la implementación de la intervención. Pero no todas las lógicas de intervención social son así. En la lógica que se ha denominado no lineal - figura 2-, la evaluación está presente en todas las fases del proceso. En este proceso la evaluación puede intervenir, por ejemplo, en el análisis del diagnóstico, donde podemos hacer una evaluación - como veremos más adelante - que llamaremos evaluación diagnóstica para conocer qué necesidades y problemas existen en la población objeto de la intervención social. Al enfrentarnos con este tipo de evaluación, nos planteamos algunas cuestiones: ¿cómo puedo planificar esa intervención?, ¿cómo puedo hacer una evaluación de esas características? Para dar respuesta a estas preguntas, lo primero que haremos es un plan de evaluación de un contexto social, o lo que es lo mismo, un proyecto para la evaluación de ese contexto social.

También podemos hacer una evaluación del diseño del plan de intervención planificado, porque efectivamente un experto elabora el plan de intervención, pero, ¿̇estamos seguros de que los objetivos planteados en el plan de intervención responden a las necesidades o los problemas de esa población?, o, por el contrario, ¿’es un plan que responde a unos intereses particulares? Y los recursos, ¿son suficientes para cubrir los objetivos del plan? Éstos son los ámbitos donde también tiene cabida la evaluación. Intervenir sobre el diseño de un plan de intervención es necesario por múltiples razones, pero la más importante es que puede prevenir una mala o pésima intervención social.

Pero la evaluación no termina en el diseño del plan de intervención (evaluación de diseño), sino que, como queda reflejado en la figura 2, también tiene cabida en la implementación del plan. El plan de intervención ha sido evaluado y aplicado en la organización para la que fue diseñado; ahora podemos analizar si su desarrollo funciona como estaba previsto. Lo que interesa saber es si el plan de intervención se está aplicando como fue diseñado y en la línea de los resultados esperados. Esperar a obtener resultados implicaría esperar a que el plan termine en su conjunto, y en ese caso ya no se podría intervenir para modificarlo. Pero si, por el contrario, el plan se evalúa durante su aplicación, se podrá redefinirlo si no funciona o se aparta de los objetivos previstos. Esta evaluación es complicada, pero, al menos teóricamente, nos dice si tendríamos que modificar alguna parte del plan de intervención o continuarlo tal como está diseñado.

Por último, podemos mencionar la evaluación de resultados y la de impacto, que pretenden determinar si el plan ha logrado los objetivos que formulamos en su diseño, en términos de resultados finales e impacto. Con la realización de esta fase completamos la lógica de la intervención no lineal. En una primera aproximación puede 
parecer confuso, pero, al observar el gráfico siguiente, podemos comprobar de manera sintetizada y clara los diferentes ámbitos del plan de intervención donde la evaluación puede intervenir, y de esta manera la evaluación se convierte en el elemento clave de la toma de decisiones y de la gestión de la intervención social. Por la centralidad que adquiere la evaluación en esta lógica de intervención, sus efectos implícitos también se multiplican, sobre todo el de la imposición de un modelo de intervención o de gestión de la intervención, al controlar de una manera directa todos y cada uno de los pasos de la intervención social.

Figura 2. La lógica no lineal de la intervención social: la evaluación intregada en el proceso de intervención

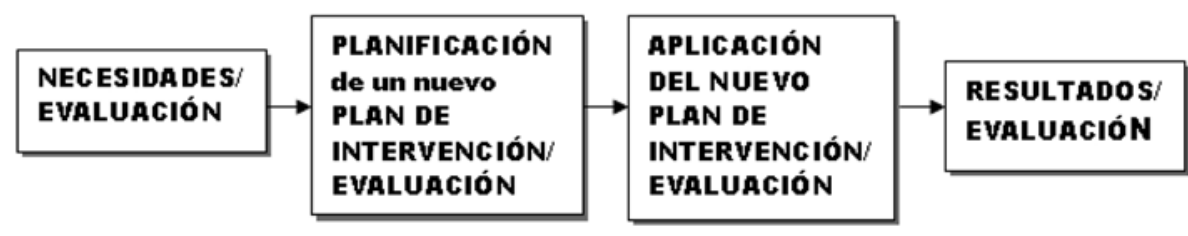

Siguiendo con la lógica de la evaluación integrada en el proceso de gestión de la intervención social, se hace necesario definir cada tipo de evaluación. Así, en la etapa de diseño de la intervención social, la evaluación de diagnóstico y la evaluación de diseño constituyen el eje de las posibles evaluaciones. Cuando un programa de intervención social en su conjunto ha puesto en marcha algún cambio pero lleva poco tiempo funcionando en esas condiciones, la evaluación de la implementación constituye las más adecuada. Por último, cuando los cambios en el programa están perfectamente asimilados y éste lleva tiempo funcionando, lo lógico es centrarse en la evaluación de seguimiento, resultados, impacto y evaluación económica. En resumen, podemos diferenciar cuatro tipos de evaluaciones: la evaluación de DiAgNóstico es aquella que tiene como finalidad definir y conocer las necesidades de un grupo o contexto social para hacerle frente. Este tipo de evaluación refleja el proceso de definición del problema, el grupo al que afecta y la necesidad de una intervención social. En definitiva, responde a las siguientes preguntas evaluativas: ¿cuál es el problema/as social/es?, ¿cuáles son las necesidades derivadas del problema social?, ¿cuáles son las causas del problema?, ‘a quién afecta y en qué medida?

La evaluación de DisEÑo es la que tiene como finalidad detectar y conocer las posibles debilidades del programa antes de su implementación. La evaluación de diseño entra dentro de lo que hemos denominado la lógica de la intervención social, cuya intención es mejorar los programas en la fase de planificación y, de esta manera, controlar la calidad de los procesos de actuación en un contexto social determinado. La 
evaluación de diseño es un medio para asegurar usos más prudentes con los escasos medios humanos y materiales disponibles, así como para ayudar con este tipo de evaluación a conseguir intervenciones sociales técnicamente más factibles que logren sus objetivos con mayor probabilidad. En resumen, la evaluación de diseño da respuesta a las siguientes preguntas evaluativas: ¿es ésta la mejor alternativa posible para dar respuesta a las necesidades objeto de la intervención social?, ‘es viable la aplicación de la alternativa en ese momento?

La evaluación de la implementación es aquella que permite saber si el funcionamiento de la intervención social o del programa está resultando como se preveía en un tiempo y contexto determinados. Uno de los aspectos clave de un programa de intervención es su implementación, en otras palabras, la puesta en marcha del programa de intervención social siguiendo los esquemas teóricos previamente fijados en su diseño. La evaluación de la implementación también tiene que ver con la calidad de la intervención social. Un programa puede no conseguir los efectos deseados/buscados debido simplemente a que no se ha puesto en marcha tal y como se había diseñado previamente. Esperar hasta que se haya completado su aplicación puede resultar caro y poco útil, por lo que la evaluación de la implementación puede ser de gran utilidad. En cierta medida, la evaluación de la implementación se asemeja a la que otros autores llaman formativa. ${ }^{1}$ En síntesis, la evaluación de la implementación debe dar respuesta a las siguientes preguntas evaluativas: ¿quién o quiénes son los responsables de la implementación?, ¿se ha aplicado el programa como estaba diseñado?, ¿qué medios se usan para asegurar que el programa se lleva a cabo de acuerdo con lo planificado?, ¿los resultados intermedios van en la línea de los esperados?

La evaluación de ReSultados es la que pretende determinar si el programa ha logrado los objetivos formulados en su diseño, en términos de resultados y efectos. En otras palabras, es el proceso evaluativo orientado a medir los resultados de las intervenciones sociales en cantidad, calidad y extensión, según las reglas preestablecidas. Por ello, la característica principal de este tipo de evaluación es la medida de los resultados, pues permite comparar el grado de realización alcanzado con el grado de realización deseado. Abarca todos los efectos de la ejecución del programa o intervención social, ya sean los objetivos globales o específicos, los directos o indirectos o los positivos o negativos. En conclusión, en este tipo de evaluación las preguntas evaluativas a responder sonः ¿podemos asegurar que hemos alcanzado los objetivos?, ¿podemos calificar de éxito o fracaso la intervención social?, ¿se han resuelto las necesidades sociales objeto de la intervención?, ¿hay que terminar o continuar con el programa?

1 Según otros autores, también podría denominarse evaluación de proceso. 
Cuadro 1. Tipos de evaluaciones según finalidad y momento de su aplicación

\begin{tabular}{|l|l|l|}
\hline TIPO DE EVALUACIÓN & \multicolumn{1}{|c|}{$\begin{array}{c}\text { MOMENTO } \\
\text { DE SU APLICACIÓN }\end{array}$} & FINALIDAD \\
\hline DIAGNÓSTICO & Antes de la intervención social. & $\begin{array}{l}\text { Se utiliza para conocer las necesidades } \\
\text { o los problemas de la ciudadanía. }\end{array}$ \\
\hline DISENO & Antes de la intervención social. & $\begin{array}{l}\text { Nos permite conocer la adecuación } \\
\text { del programa de intervención social a } \\
\text { las necesidades de la población. }\end{array}$ \\
\hline IMPLEMENTACIÓN & Durante la intervención social. & $\begin{array}{l}\text { Proporciona la información para saber } \\
\text { cómo se está aplicando el programa. }\end{array}$ \\
\hline RESULTADOS & Final de la intervención social. & $\begin{array}{l}\text { Permite saber qué efectos/ } \\
\text { consecuencias ha tenido la } \\
\text { intervención social (programa) sobre } \\
\text { el contexto social intervenido. }\end{array}$ \\
\hline
\end{tabular}

Para poder minimizar los efectos implícitos de la evaluación se hace necesario construir una nueva lógica en la intervención social en la que la negociación adquiera centralidad en todo el proceso. Esta lógica queda recogida de forma gráfica en la figura 3. Según el Diccionario de Sociología (editado por Giner, Lamo de Espinosa y Torres, 1998), una negociación es una serie de intercambios entre partes con intereses diferentes para llegar a un acuerdo. La negociación es posible si existe un acuerdo beneficioso para todas las partes en comparación con la situación de desacuerdo, es decir, si cada parte puede obtener algo que valora mucho a cambio de ceder en algo que valora menos. El arte de la negociación consiste en anticipar la consecución de un acuerdo favorable para todas las partes, mediante la adecuada definición de las dimensiones del tema y la elección de un procedimiento de negociación que disminuya los costes de negociar. Aplicando este proceso de negociación a la evaluación, estamos rompiendo la lógica impositiva y dando paso a la participativa; en otras palabras, pasamos de la evaluación que impone un modelo de gestión a la evaluación que negocia un modelo de gobernanza.

Figura 3. La lógica no impositiva de la evaluación: la negociación integrada en el proceso de evaluación/intervención

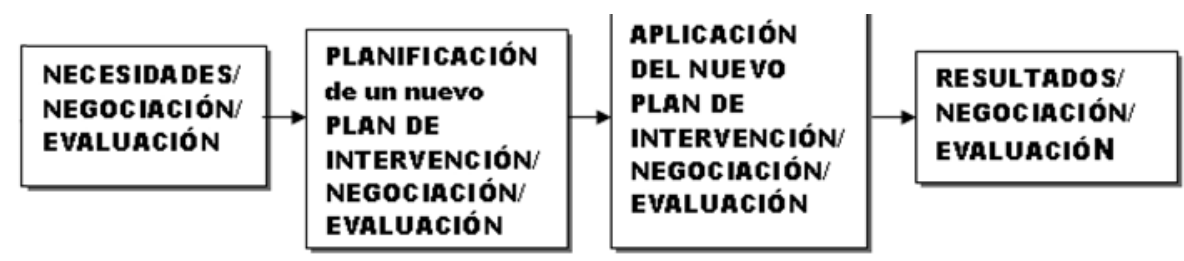


Otra de las funciones que cumple la evaluación es construir la cultura evaluadora de las organizaciones prestadoras de servicios públicos. La frase de que nadie quiere ser evaluado es un axioma dentro de la evaluación. Para evitar la resistencia y oposición a la evaluación, lo primero que se debe hacer es aumentar la cultura evaluativa; para ello, nada mejor que superar la idea — construida sobre todo en nuestra sociedad por el sistema educativo - de evaluación como sinónimo de sanción, y dar paso al concepto de evaluación participativa. En este sentido, todos los especialistas en evaluación recomiendan, antes de iniciar cualquier actividad evaluadora, llevar a cabo un proceso de negociación con todos los implicados: es aconsejable negociar el modelo de evaluación antes que luchar contra la resistencia de los implicados. Este proceso irá desapareciendo en la medida en que la evaluación pase a formar parte de la lógica de la intervención social defendida en este capítulo.

La negociación, como proceso básico para construir una cultura evaluadora y evitar los efectos implícitos de la evaluación, es un todo de diálogo y acuerdos que efectúan los evaluadores y los implicados en la evaluación —antes, durante y después de ésta-, con el objetivo de evitar los rechazos, las reticencias, los prejuicios y las expectativas falsas de los distintos intereses que integran la vida de las organizaciones públicas. En definitiva, se pretende aumentar la cultura evaluativa de la comunidad para evitar asociar evaluación con sanción, y para que nadie se pueda sentir amenazado o agredido en su independencia y autonomía e implicarla en todo el proceso de gestión de la intervención social. Para que el proceso de negociación cumpla todas sus pretensiones, no debe ceñirse sólo a las dimensiones o los aspectos a evaluar, sino que debe ampliarse a aspectos como:

1. El tipo y la naturaleza de la evaluación.

2. Los intereses por los que se pone en marcha la evaluación.

3. Los fines y objetivos de la evaluación.

4. Los métodos, las técnicas y los instrumentos de recogida de información.

5. El equipo de evaluación.

6. La temporalización de la evaluación.

7. Las estrategias para la discusión y el consenso de los informes.

8. Los sistemas y las formas de reconducir los acuerdos y abordar las discrepancias.

9. La colaboración requerida a los participantes y los compromisos por ellos asumidos.

10. Las formas de difundir la información obtenida internamente.

11. La expansión social de los informes y de los descubrimientos y las evidencias. 
La multitud de aspectos que cabe considerar en la etapa de la negociación permite concluir con la consideración de que la negociación puede ser un medio eficaz para conseguir una evaluación de la calidad que sirva de ayuda a todos los que trabajan y comparten una misma realidad. El evaluador, al planificar el trabajo, deberá evitar la rigidez, o mejor dicho, deberá ser «rígidamente flexible», sin olvidar la jerarquización existente en las organizaciones, que puede generar un proceso de negociación y desarrollo de la exploración en sentido vertical. En la negociación inicial se acordará cuándo, cómo y a quién se entregarán los informes. Igualmente, hay que evitar la ocultación en el proceso de evaluación. En la negociación debe quedar claro qué se pretende y cómo se piensa conseguir. Para evitar generar expectativas falsas, conviene explicar a los implicados claramente qué pueden esperar razonablemente del trabajo del equipo.

Asimismo, conviene que el equipo de evaluación se reúna con frecuencia para contrastar opiniones respecto a lo que sucede en la intervención y, sobre todo, a la forma en que se está desarrollando el trabajo de evaluación. Cuando se hayan cometido errores, es preferible disculparse por ellos, sean de la naturaleza e intensidad que sean. Cuando surgen problemas a propósito de la evaluación, hay que plantearse cuál es su origen y de dónde proceden y recordar que la ética exige que la confidencialidad de los datos se guarde escrupulosamente. Por todo ello se aboga por una perspectiva de evaluación participativa donde el consenso sea la base de todo el proceso e impida la implantación de un sistema de gestión no negociado; proceso que llevará a una identificación con la organización en todos sus ámbitos de actuación, por lo que se propone un modelo de evaluación basado en el consenso y la participación.

En definitiva, la evaluación participativa debe orientarse bajo los siguientes criterios:

1) Responder a las necesidades y los intereses de todos los implicados. La evaluación debe ser útil. Se precisa que esté dirigida a aquellas personas y grupos relacionados con la realización de lo que se está evaluando y que se les informe no sólo acerca de las virtudes y los defectos, sino de las soluciones para mejorar. Para conseguir tal utilidad, la evaluación debe proporcionar las informaciones prácticas que necesitan los implicados e interesados en ella. En primer lugar, señalar la necesidad de describir los colectivos afectados para que todas sus necesidades puedan ser satisfechas. En este sentido, Robert Stake señala la utilidad como uno de los principios que debe cumplir toda evaluación: los estudios de evaluación, más que simples investigaciones, deben ser un servicio que proporcione la ayuda necesaria y la información útil tanto a los implicados como a los responsables de la intervención social. Para ello es necesario utilizar el contenido de los informes de evaluación como punto de referencia para alimentar y proponer dudas, interpretaciones, hechos y recomendaciones. La publicidad de los informes que genera la evaluación es necesaria, no sólo por el derecho de la sociedad 
en general a conocer el valor de las intervenciones, sino porque puede contribuir a un mayor conocimiento y a crear una estructura social de relaciones y participación, de forma que se eviten malos entendidos. Un informe no debe ser la conclusión inapelable y taxativa de la evaluación. Santos (1990) aconseja que los evaluadores sean conscientes de esto y acepten el compromiso de que el informe y la evaluación en su conjunto deben ayudar a la introducción y generalización de procesos y dinámicas democráticas de conocimiento y reflexión. Así no sólo estarían sirviendo a la sociedad, y enriqueciendo a los participantes, sino que ellos mismos aprenderían.

Para cumplir todas las funciones, el informe ha de cuidar que el lenguaje sea accesible no sólo a los directamente implicados en la realidad evaluada, sino a cualquier otro ciudadano interesado en el conocimiento de dicha realidad. En este sentido, Angulo (1991) apunta que la calidad del trabajo de los evaluadores no puede cifrarse en la ilegibilidad o dificultad de comprensión de un informe, sino en la capacidad de situar a los lectores en la realidad evaluada, los logros, los errores, las dificultades y las aspiraciones.

2) Orientar todo el proceso organizativo de la intervención social y que sea viable su aplicación. La viabilidad del proceso de evaluación depende de que la evaluación sea realista, práctica, prudente, diplomática, moderada y, sobre todo, que esté integrada en el conjunto de la intervención social. Debe ser práctica para que los problemas sean mínimos y pueda obtenerse la información necesaria. Es necesario planificarla y dirigirla conociendo las distintas posturas de los diferentes grupos de interés, con el fin de obtener su cooperación y evitar las posibles influencias de estos grupos en los resultados.

Una de las formas de asegurar la viabilidad de la evaluación es «vendiendo» la evaluación como un modo de contribuir a la «salud y calidad» de lo evaluado, informando a los profesionales sobre los objetivos, las actuaciones y los resultados de la evaluación; de igual manera, hay que proporcionales los medios necesarios para remediar las deficiencias detectadas en cada evaluación. "La evaluación es la compañera de todo esfuerzo»; con este mensaje Stake defiende que lo pequeño puede ser considerado con frialdad o con pasión por el evaluador, pero que todo ha de ser analizado. En ocasiones, se tiende a convertir las complejidades naturales en simplificaciones que falsifican la realidad, con la justificación de que simplificando es más fácil establecer conclusiones o emitir juicios. Es necesario, para evitar esto, la utilización de procedimientos metodológicos sensibles a la riqueza, la complejidad estructural y las interacciones que se producen en toda realidad social. Contreras (1991) recomienda utilizar procedimientos lo suficientemente sensibles como para captar las valoraciones, las aspiraciones, las interpretaciones y los intereses de las personas tal como son expresados por ellas mismas, sin presuponerlos de antemano. 
Para Stake, la reiteración en el encuentro permite conocer y descifrar las claves de la realidad; esta continuidad debe instaurarse en evaluaciones continuas de las intervenciones sociales que involucren a los profesionales en el proceso de mejorar su actuación. No podemos olvidar la atención a los criterios éticos que conformarían los límites de su desarrollo, pretendiendo con ello no sólo asegurar su aplicación democrática, sino mantener en lo posible el difícil equilibrio entre el derecho a la privacidad y la necesidad de conocimiento y responsabilidad social de aquellos que están implicados en la realidad evaluada. Esta dualidad también es reflejada por Simons (1982) al entender que la evaluación debe dar cuenta de la acción pública, encontrando vías para incrementar la información al exterior de las instituciones, pero teniendo en cuenta que la evaluación y crítica internas son mucho más importantes. La información al exterior debe proporcionarse con ciertos recaudos, dependiendo del ambiente local y de la naturaleza de los problemas que fueron objeto de la evaluación.

3) Facilitar las decisiones públicas y profesionales a partir de la ética profesional del evaluador. La ética de la evaluación debe basarse en un compromiso explícito que asegure la necesaria cooperación, la protección de los derechos de las partes implicadas y la honradez de los resultados. Las obligaciones derivadas de las distintas etapas de la evaluación — qué evaluar, cómo evaluar, quién evalúa y cuándo- deben ser plasmadas, a juicio de los expertos, en un compromiso escrito, para cumplirlas o renegociarlas formalmente, sin que esto signifique rigidez en el diseño, al entender que la evaluación ha de diseñarse con la suficiente flexibilidad como para permitir respuestas a situaciones no esperadas (un enfoque progresivo más que un diseño prefijado).

Otros aspectos a resolver, desde la ética profesional, son los conflictos de interés, que deben afrontarse abierta y honestamente para que no interfieran en el proceso. Stufflebeam (1987) recomienda, en relación con los informes de evaluación — tanto orales como escritos-, la necesidad de ser francos, directos y honestos en la revelación de las conclusiones pertinentes, incluyendo las limitaciones de la evaluación, para lo cual es necesario utilizar un lenguaje accesible a las audiencias, con el propósito de asegurar el derecho del público a conocer la realidad evaluada.

Cada aspecto de un programa contiene al menos tantas verdades como puntos de vista. El evaluador está obligado a conseguir un consenso explicativo, es decir, a tener en cuenta la variedad de explicaciones y a mostrar cómo y por qué se producen. $\mathrm{H}$. Simons (1982), atendiendo a la diversidad de la realidad social, apuesta por una evaluación democrática y sostiene que debe asegurarse tanto la discusión franca y abierta acerca del programa, como el derecho de los individuos a la privacidad.

4) Aclarar la definición de objetivos, proceso y contexto. Las normas señaladas por la mayoría de expertos en este apartado están concebidas para asegurar que la evaluación revele y transmita una información técnicamente exacta acerca de las caracterís- 
ticas de la intervención social, para poder determinar su valor o su mérito, señalando como normas:

1. Identificación del objeto a evaluar.

2. Análisis del contexto donde se desarrolla la intervención social.

3. Descripción de intenciones y procedimientos a seguir en la evaluación.

4. Identificación de fuentes de información fiables.

5. Determinación de la validez de los instrumentos de evaluación.

6. Determinación de la exactitud y control sistemático de los datos.

7. Análisis de la información cualitativa y cuantitativa.

8. Conclusiones justificadas.

9. Objetividad en el informe.

La evaluación es la declaración del valor de algo. Existen varias dimensiones del mérito y del demérito de las cosas. Para juzgar el mérito deben existir criterios explícitos, si bien es cierto que deben tenerse en cuenta el contexto y las particularidades del programa. El juicio del mérito o demérito no debe ser del evaluador, sino que debe facilitarse que sean los implicados los que lo hagan. Desde esta perspectiva, Angulo y Contreras (1991) consideran que una evaluación pregunta sobre el sentido y el valor de las realidades objeto de evaluación, con el fin de orientar la recolección de las evidencias, las informaciones y los puntos de vista que permitan a los interesados ampliar y matizar su comprensión, profundizar en su reflexión, elaborar apreciaciones más informadas y dirigir sus actuaciones futuras de forma colectiva y en colaboración.

La razón para optar por un juicio compartido se basa en que ni la verdad ni la valoración correcta están en posesión de grupos o personas privilegiadas, ya sean los evaluadores, los patrocinadores o los sujetos implicados en la realidad evaluada. La verdad y la valoración son asunto de construcción democrática de todos.

\section{Los enfoques participativos de evaluación}

¿Al servicio de quién está la evaluación? Esta pregunta se la han planteado la mayoría de los teóricos de la evaluación. Stufflebeam (1987) considera la evaluación al servicio de los directivos de la administración, que la pueden utilizar como vía para imponer un modelo de gestión; en cambio, Stake (1975) considera que los receptores de la evaluación son múltiples. McDonald (1991), que reconoce la evaluación como actividad ética, presta atención a la influencia de los evaluadores en la distribución de los recursos y a la sensibilidad a las consecuencias personales e institucionales de los resultados de la evaluación. En este sentido, House (1994) entiende que «la evaluación es una parte 
de una situación pública, una decisión colectiva”. House concibe la evaluación como una actividad persuasiva y hace una clarificación del grado y el carácter del saber que podemos esperar de una evaluación. Tiene en cuenta la evaluación como actividad de servicio, así como sus múltiples destinatarios con valores e intereses diferentes. La evaluación no puede producir proposiciones de obligado cumplimiento; en consecuencia, este autor considera que la evaluación:

- Persuade en vez de convencer.

- Afirma en vez de demostrar.

- Es creíble en vez de segura.

- Tiene una aceptación variable en vez de obligada.

En esta misma dirección, la evaluación debe reforzar la posibilidad de un amplio debate sobre cuestiones importantes y consecuencias comunes. Todos estos planteamientos teóricos fueron el origen del resurgir de la evaluación cualitativa o naturalista, que defiende una evaluación participativa y alejada de la imposición de los modelos que refuerzan los efectos implícitos de la evaluación. En esta línea de lo que se denominan enfoques cualitativos o naturalistas se han seleccionado los siguientes enfoques:

a) Enfoque que prescinde de los objetivos.

b) Enfoque de estudio de casos.

c) Enfoque basado en el pensamiento estratégico.

a) Enfoque que prescinde de los objetivos

El enfoque que prescinde de los objetivos — evaluación libre de objetivos - constituye una reacción directa frente a la omnipresencia de la evaluación determinada por los objetivos - evaluación por objetivos-. Se basa en el principio de que el conocimiento previo de los objetivos introduce sesgos en la evaluación, por lo que el evaluador debe ignorarlos de forma deliberada. El trabajo del evaluador consiste en la investigación sobre los resultados, sin discriminar si se trata de efectos directos o colaterales, en otras palabras, en valorar resultados sin tener en cuenta las intenciones.

El modelo libre de objetivos reduce el sesgo de buscar sólo los intereses del responsable del programa, especificados de antemano, ya que éstos no se comunican al evaluador. Por lo tanto, el evaluador debe investigar todos los resultados. Muchos de ellos no son sino efectos colaterales imprevistos, que pueden ser positivos o negativos. De todos los enfoques de evaluación, éste es el menos utilizado. Para muchos investigadores sociales resulta difícil imaginar dónde puede el evaluador encontrar criterios de evaluación fuera de los objetivos del responsable. Ante esta cuestión, Scriven ha tratado de desarrollar el concepto de necesidad como fundamento de la evaluación. Frente a los simples gustos o deseos, las necesidades se descubren mediante su evaluación. El 
establecimiento de la validez objetiva de tales necesidades proporcionaría al evaluador una fuente autorizada de normas. Por lo tanto, la evaluación independiente de los objetivos se basa en el análisis de las necesidades del usuario y no de los objetivos de los responsables.

Uno de los máximos defensores de este enfoque es Scriven (1989). Sostiene que el evaluador no sólo no tiene que basar su evaluación en los objetivos del programa, sino que debe procurar evitar deliberadamente informarse sobre ellos, con el fin de que no le lleven a sesgos tendenciosos. En este sentido, concibe al evaluador como un experto en la prevención y eliminación de sesgos en la evaluación, cualquiera que sea su procedencia. La fuente de normas y criterios de evaluación sería el análisis de las necesidades objetivas del usuario o beneficiario del programa que se evalúa, prescindiendo de los objetivos de su promotor.

En la evaluación sin objetivos el punto fundamental es la independencia entre los actores que intervienen en la evaluación, para asegurar la objetividad e imparcialidad del evaluador, que debería actuar como lo haría un juez instructor, identificando el encadenamiento entre causa y efecto.

Las características que mejor definen este enfoque las podemos resumir en:

La evaluación independiente de los objetivos se basa en el análisis de las necesidades del usuario y no en el de los objetivos de los diseñadores del programa.

Los objetivos del programa no se comunican al evaluador; por ello éste debe investigar todos los resultados, con independencia de que sean directos o imprevistos.

La independencia del evaluador es su seña de identidad.

La metodología de este sistema de evaluación no es tan claro como en otros enfoques y las técnicas que se utilizan son muy diversas; entre las más frecuentes, las de tipo «doble ciego», en las cuales ni el sujeto ni el investigador saben cuál es el tratamiento ni el placebo.

Entre las técnicas de evaluación utilizadas predominan las cualitativas.

Un campo de aplicación de este enfoque ha sido la evaluación de servicios desde el punto de vista de los consumidores o usuarios del programa.

Los criterios de evaluación se basan en las necesidades objetivas de los usuarios o beneficiarios de los servicios o del programa.

Uno de sus defensores es Scriven, que considera que la evaluación no debe centrarse sólo en los objetivos del programa.

Del enfoque que prescinde de los objetivos destacan dos limitaciones. La primera, que en el transcurso de la evaluación los evaluadores son continuamente solicitados, por lo que deben intentar mantener una renovada vigilancia sobre la evaluación. La segunda, que los evaluadores actúan de modo semejante al de un detective que ha de descubrir claves y extraer información, o como un juez instructor que trata de deter- 
minar conexiones en condiciones no experimentales. Por medio del modus operandi, tanto el evaluador como el investigador han de establecer una relación causal entre causa y efecto.

De igual modo se persigue la independencia del evaluador/personal del programa, tomando como destinatarios de la evaluación a los beneficiarios del programa. Sin embargo, esto tiene sus limitaciones en determinadas áreas de evaluación. Hay áreas en las que resulta más evidente el uso de este modelo, como por ejemplo a la hora de valorar productos de consumo por parte de sus usuarios; otras, por el contrario, presentan dificultades, como las referidas a los servicios sociales.

b) Enfoque de estudio de casos

El enfoque de estudio de casos o negociación se centra en la revisión de las partes de las que consta el programa, utilizando la percepción de los sujetos que participan en él y la del propio evaluador. Pretende mejorar la comprensión del programa que tienen los destinatarios, presentándolo tal como lo ven otros. En palabras de House (1994), «el objetivo de este enfoque consiste en mejorar la comprensión que de la evaluación tenga el lector o destinatario, mostrándoles, ante todo, cómo perciben otros el programa sometido a evaluación».

La cuestión principal que se plantea es: ¿qué le parece el programa evaluado a los sujetos que tienen contacto habitual con él? La metodología usual consiste en llevar a cabo entrevistas con muchas personas, hacer observación in situ y presentar los hallazgos en forma de estudio de casos. El estudio de casos es casi completamente cualitativo por metodología y presentación. Los estudios de casos presentan descripciones complejas y holísticas que implican gran cantidad de variables interactivas. Los datos se obtienen mediante la observación personal y la redacción es informal y narrativa, y en ella a menudo se emplean citas, ilustraciones, alusiones y metáforas. Las comparaciones son más implícitas que explícitas.

Stake (1975) destaca entre los partidarios de este enfoque. Para él, «los estudios de casos presentan descripciones complejas, holísticas, que implican gran cantidad de variables interactivas, y se centran en la percepción y el conocimiento como proceso de negociación entre las partes».

Los principios básicos en los que se basa este enfoque son:

1. Se centra en los mismos procesos del programa y en la visión que las personas tienen de éste.

2. Se usa una metodología cualitativa, etnográfica y «naturalista». 
3. Emplea como técnicas las entrevistas, la observación in situ y la revisión documental.

4. Presenta los resultados de la evaluación en forma de «estudio de casos» (redacción informal, narrativa y con empleo frecuente de citas, ilustraciones y metáforas).

5. Está en sintonía y equilibrio epistemológico con la experiencia del usuario.

6. Procura que estén representadas todas las partes con intereses en la evaluación.

7. Su objetivo, más que la explicación, es la mejora de la comprensión por parte de los implicados en el programa.

El enfoque holístico de McDonald (1991) es un modelo cualitativo y podemos enmarcarlo dentro del enfoque de estudio de casos. McDonald considera la evaluación como un proceso donde se deben tener en cuenta todos los datos que inciden o pueden hacerlo en el proyecto, en los programas y en los contextos. La misión del evaluador es recoger información y comunicarla a las personas interesadas en el programa para, de esta forma, orientar su toma de decisiones.

El método holístico concibe los programas y las organizaciones sociales como una conjunción de todas las variables y relaciones que potencialmente les pueden influir. Implica, por lo tanto, la consideración de todos los datos que inciden directa o indirectamente en el programa.

En este enfoque, un programa u organización social se considera como un todo en el que todas las partes — profesionales, usuarios, instalaciones, cargos directivos - , así como su contexto, deben formar parte de la evaluación. Hay otros autores que también inciden en la evaluación como un todo, como Parlett y Hamilton (1976), quienes insisten en la consideración de la evaluación como un todo en el que todas las partes, todos los sujetos implicados y todas las fases del desarrollo de un programa deben ser tenidos en cuenta de manera global.

La figura más señera de este tipo de evaluación es Stake (1975), quien, a su vez, puede considerarse una de las figuras americanas más importantes en el campo de la evaluación de los años sesenta. Stake, en su artículo «La figura de la evaluación educativa», publicado en 1967, desarrolló su método, que más tarde en 1973 amplía y presenta en la conferencia sobre evaluación de Gotemburgo y que explica dos años más tarde en la publicación Evaluación de programas: particularidades de la evaluación respondiente.

Su filosofía evaluativa ha recibido influencias de Cronbach, Tyler y Scriven. Su modelo de la figura de la evaluación está a medio camino entre la evaluación con referencia a objetivos de Tyler y la propia ampliación de su método, la evaluación respondiente. Entre las ideas que Stake mantiene o matiza de estos autores, destacan: 
- Cronbach afirma que las evaluaciones comparativas de programas alternativos no resultan informativas. Stake insiste en el ataque a los experimentos comparativos.

- Tyler sostiene que los evaluadores deben comparar los resultados observados. Stake añade a esta afirmación que los evaluadores también deben valorar los antecedentes y las continuas operaciones, tanto las propuestas como las reales.

- Scriven indica que evaluar sin emitir juicio no tiene sentido. Stake está de acuerdo, aunque cuestiona lo acertado de asignar la responsabilidad del juicio sólo a los especialistas en evaluación.

En su concepción de evaluación destacan dos actos básicos o partes. El primero es la denominada matriz de descripción, que engloba las intenciones, lo que se planea y pretende y las observaciones, lo que realmente se observa o percibe. El segundo, el referido a la matriz de juicio, engloba tanto las normas utilizadas para emitir el juicio como los propios enjuiciamientos formulados sobre el programa. Para enjuiciar las intenciones, Stake recomienda investigar y utilizar las finalidades o la base lógica del programa.

Con el fin de atender a la eficacia de la evaluación, Stake relaciona las operaciones básicas de descripción y juicio con tres conceptos fundamentales: a) antecedentes, que se refieren a cualquier condición previa al programa y que pueden influir en los resultados; b) transacciones, que son las diversas relaciones, compromisos y encuentros que tienen lugar entre los distintos miembros durante el proceso de desarrollo del programa, y c) resultados, que son los efectos de un programa. Estos conceptos constituyen tres fuentes de información básicas para realizar un proceso evaluativo, continuo, dinámico y sobre la totalidad del programa, ya que proporcionan información al principio, durante el desarrollo y al final de éste.

En el momento de dar la información a nivel descriptivo, es necesario hacer dos tipos de análisis:

a) De congruencia, cuya finalidad es averiguar si los propósitos se han cumplido.

b) De contingencia, con el que se trata de identificar los resultados contingentes a antecedentes concretos $y$ a determinados procesos.

Otra idea introducida por Stake es la de evaluación respondiente, llamada así porque la evaluación debe responder a los problemas y las cuestiones reales que puedan planteárseles a las personas implicadas en un programa. La evaluación respondiente presenta las siguientes peculiaridades según Pérez Gómez (1985):

- Se centra en la descripción de las actividades más que en la definición de los objetivos o las intenciones del programa.

- Enfatiza más los problemas que las teorías. 
- Contempla las diferentes interpretaciones de las personas implicadas en el programa.

- Responde a las necesidades de información y al nivel de conocimiento de las personas interesadas en el programa.

- Enfatiza la necesidad de proporcionar a los interesados la experiencia del programa, implicándolos en su análisis y valoración.

- Describe y ofrece un retrato completo y holístico del programa.

La irrupción de Stake en el campo de la evaluación lo ha convertido en el líder de una nueva escuela de evaluación que exige un método pluralista, flexible, interactivo, holístico, subjetivo y orientado hacia el servicio.

Una de las principales limitaciones del estudio de casos es la autenticidad: el establecimiento de las bases que permitan fiarse de los resultados de la evaluación. Otras limitaciones metodológicas tienen que ver con la fijación de los límites de la investigación y con su circunscripción a las categorías en que puedan asimilarse y comprenderse los datos. Este enfoque resuelve el problema del evaluador, pues procura representar todas las posturas significativas de valor en el estudio del caso de que se trate, extrae de esas posturas sus criterios y normas, y deja que el lector del estudio sopese y equilibre estos elementos por su propia cuenta.

$\mathrm{Al}$ ser su idea principal, como se ha dicho, responder a las cuestiones ¿qué les parece el programa a los sujetos que tienen contacto habitual con él? y ¿cómo perciben el programa?, la meta de la evaluación «es más la comprensión que la explicación y el conocimiento proposicional». Persigue una mejora de la comprensión de la evaluación por parte de su destinatario. En este sentido, Stake señala que permite presentar descripciones complejas, holísticas, que implican una gran cantidad de variables que interactúan entre sí. Ésta es una aportación que pretende dar cuenta de la complejidad de una realidad multicausal y cambiante, donde la exclusiva explicación numérica no llega a tener en cuenta todos los aspectos la realidad.

No obstante, presenta ventajas con respecto a otros paradigmas de esta metodología en cuanto a reducir posibles problemas derivados de los aspectos subjetivos de la percepción; a diferencia de, por ejemplo, el modelo de crítica de arte, donde el experto (que es el que evalúa) determina el proceder según su experiencia previa. El evaluador que hace uso del estudio de casos se basa en las percepciones de otros tanto como en las suyas propias.

c) Enfoque basado en el pensamiento estratégico

Un ejemplo de evaluación basado en la participación de todos los implicados en el programa u organización sería un modelo de evaluación que tomase como principios 
los del pensamiento estratégico, es decir, basado en la idea de que todos los implicados en el desarrollo de una actividad forman parte del proceso y en la convicción de los beneficios que conlleva la evaluación para el adecuado funcionamiento de la organización. Además, es necesario tener en cuenta que la gestión interna de los recursos de la organización no es suficiente, sino que es necesario considerar la relación con el entorno. Las organizaciones prestadoras de servicios públicos, como el resto de las organizaciones complejas, desarrollan su actividad en un contexto de incertidumbre $y$ vertiginosos cambios sociales, por lo que es preciso incluir las orientaciones a largo plazo. En este modelo se da mucha importancia a la planificación de acciones, puesto que éstas determinarán las herramientas y los procesos a seguir para alcanzar el éxito en la evaluación. Para el desarrollo del modelo de evaluación basado en el pensamiento estratégico se ha tomado como referencia una hipotética organización prestadora de servicios públicos.

Un modelo de tales características debe contemplar la totalidad de la organización. Antes de explicar su desarrollo, nos detendremos brevemente en las diferencias metodológicas entre una evaluación parcial y otra integral de la organización, y en la conveniencia de optar por la segunda. La evaluación parcial sería aquella que sólo se centra en algunos de los elementos de la organización, como el personal, los usuarios o clientes, la organización y su funcionamiento, o la toma de decisiones. En cambio, en la evaluación global se busca que todos los implicados en el desarrollo de una actividad participen en el proceso evaluativo. ${ }^{2}$

El modelo de evaluación participativo basado en el pensamiento estratégico se fundamenta en la necesidad de que todos los implicados en el desarrollo de una actividad participen tanto en el proceso de planificación como en el de ejecución. Aquellos que ejecutan una actividad conocerán con mayor precisión los problemas que tienen, que han de ser considerados en la etapa de planificación. Separar estas funciones provoca la pérdida de información o reproduce la inercia burocrática ante la necesidad de redactar múltiples informes de la situación. El modelo de evaluación integral basado en el pensamiento estratégico propuesto permite la participación de todos los implicados en el desarrollo de una actividad desde que se planifica hasta que se ejecuta.

Por otra parte, hay una visión muy limitada y clásica de la función de control. Ésta es vista como un control a posteriori de la acción, un control que tiene lugar sobre los resultados de la actividad y no durante el proceso con el seguimiento de las operaciones en marcha, y, en la mayoría de los casos, se trata de un control presupuestario. Además, se considera que la finalidad del control es garantizar que los resultados de

2 Este modelo ha sido desarrollado en algunas organizaciones complejas, como es el caso de la Universidad Politécnica de Cataluña, y se encuadraría en el enfoque del pensamiento estratégico. En dicha universidad, los departamentos y servicios evaluados elaboran un plan estratégico que contiene las acciones que hay que llevar a cabo para lograr sus objetivos o corregir los problemas detectados en su funcionamiento cotidiano. 
la actividad coincidan con lo planificado. Otro aspecto relativo al control es que tiene connotaciones muy negativas, $y$, por lo tanto, provoca cierto rechazo en aquellos que son controlados. Para evitar esto, es preciso, por una parte, participar en el proceso de evaluación y, por otra, sustituir la idea de controlar por la de evaluar. Evaluar significa emitir un juicio, pero, en la medida en que participemos en la detección y solución de nuestros problemas en la organización, podremos apreciar las mejoras y comprobar que nuestro trabajo no ha sido en vano. Se ha de evaluar con la pretensión de mejorar, no porque está de moda o como una tarea impuesta que nos supone un trabajo adicional innecesario. De ser así, la actividad de evaluación contribuirá a la desmotivación y al rechazo.

En un modelo de evaluación basado en el pensamiento estratégico, hay que tener en cuenta tres aspectos fundamentales (I. Bazaga, 1999): en primer lugar, la generación de una conciencia sobre la necesidad de planificar estratégicamente; en segundo, el énfasis en la implantación de las acciones, y, por último, el ajuste del modelo de evaluación a la cultura y los valores de la organización afectada para que el proceso llegue a su fin satisfaciendo los requerimientos y las expectativas generadas. Para ello se aplican las siguientes fases (véase tabla siguiente):

Fase 1. Generación de un consenso estratégico. Constituye un paso fundamental al iniciar un proceso costoso en tiempo, dinero y recursos. Todo el personal involucrado en la organización ha de estar convencido de los beneficios de implicarse en una evaluación que corrija los problemas de funcionamiento de ésta. Si hay sectores opuestos a la evaluación y la consideran como algo impuesto, las posibilidades de éxito serán mínimas. Los órganos que participen deben apreciar sus resultados, pensar que su esfuerzo y dedicación tendrán su repercusión sobre el conjunto de la organización. De lo contrario, se contribuirá a la desmotivación, a pensar que se haga lo que se haga no servirá para nada. En esta etapa se decide qué se va a evaluar. Los órganos implicados en el desarrollo de una actividad han detectado previamente los elementos clave, los problemas y las fricciones del sistema y han de ser ellos mismos quienes planteen las soluciones. Para ello elaboran un plan estratégico que contiene las acciones que hay que llevar a cabo para solucionar sus problemas y todos han de estar de acuerdo con el modo de proceder.

Fases 2 y 3. Análisis de la organización para la formulación de un plan estratégico. La información de la organización se debe extraer de un diagnóstico que identifique las amenazas y oportunidades que se derivan del entorno estratégico, y de un diagnóstico interno que identifique los puntos fuertes y débiles de la organización y que corresponde a la primera fase de cualquier plan de estas características. También se puede enriquecer 
con la opinión de expertos, mediante un cuestionario en este tipo de organizaciones a través del método Delphi y entrevistas en profundidad. En esta fase se debe llegar a un acuerdo sobre los beneficios de evaluar el proceso, y, una vez detectados los problemas y las fricciones existentes en el trabajo cotidiano, elaborar un plan estratégico con una serie de acciones evaluativas que permitan corregir esos problemas.

Fase 4. Implantación de las acciones estratégicas. Una vez diseñado el plan estratégico, se procede a la formulación de las acciones y a su implantación, es decir, se especifica cómo se van a llevar a cabo. Como se ha dicho, tanto la formulación de las acciones estratégicas como su implementación son el resultado de la reflexión conjunta de todos los participantes en el proceso. No se trata de elaborar planes muy ambiciosos, sino de agilizar el funcionamiento de determinados procesos mediante la aportación de soluciones reales a problemas concretos que tengan en cuenta la opinión del personal implicado, desde el que planifica la acción hasta el que la ejecuta. Al final del proceso se vuelven a reunir todos y los resultados obtenidos se tendrán en cuenta en la siguiente fase planificadora.

Fase 5. Evaluación de los resultados. Para evaluar las acciones puestas en marcha en la fase anterior se lleva a cabo una evaluación formativa, es decir, una evaluación que emite una valoración sobre cada una de las acciones y estrategias en su puesta en marcha. $\mathrm{Su}$ objetivo es controlar su buen funcionamiento y establecer su modificación en caso necesario en cualquier momento del proceso. La valoración final ha de ser conocida por aquellos que han participado en la evaluación. Una vez evaluadas las acciones incluidas en el plan estratégico, se vuelven a reunir todos los participantes y se hace una puesta en común de todos los problemas o contratiempos que hayan surgido. La retroalimentación de la información durante todo el proceso es indispensable. Se necesita revisar regularmente el diagnóstico estratégico en función de la evolución del entorno competitivo y confrontar sistemáticamente las realizaciones con las previsiones, aunque esto implique la modificación de algunos objetivos y la corrección de algunas acciones. El resultado final será alcanzar la visión de éxito del órgano o de la actividad a evaluar. No todas las partes de la organización tienen que someterse a un proceso de evaluación, sólo aquellas que presenten un desfase entre el diseño y su puesta en práctica. Con el paso del tiempo y cuando se hayan llevado a cabo varias evaluaciones, este modo de proceder se habrá naturalizado y no supondrá ningún esfuerzo para la organización, sino que formará parte de su quehacer cotidiano y aportará agilidad a su funcionamiento general. 


\section{Cuadro 2. Construcción social de un modelo de evaluación participativa basado en el pensamiento estratégico}

\begin{tabular}{|l|c|}
\hline ÁMBITO DE LA ORGANIZACIÓN & $\begin{array}{c}\text { ÁMBITO DE LA } \\
\text { EVALUACIÓN }\end{array}$ \\
\hline $\begin{array}{l}\text { FASE 1: } \\
\text { Generación de un consenso estratégico y evaluativo en la } \\
\text { organización. }\end{array}$ & \begin{tabular}{l} 
Iniciar en la evaluación participativa \\
\hline $\begin{array}{l}\text { FASE 2: } \\
\text { Análisis de la organización para conocer sus puntos fuertes } \\
\text { y débiles. }\end{array}$
\end{tabular} \\
\hline $\begin{array}{l}\text { FASE 3: } \\
\text { Elaboración de un plan estratégico para la organización. }\end{array}$ & $\begin{array}{l}\text { Evaluación } \\
\text { Diagnóstico }\end{array}$ \\
\hline $\begin{array}{l}\text { FASE 4: } \\
\text { Aplicación del plan estratégico. }\end{array}$ & Negociación \\
\hline $\begin{array}{l}\text { FASE 5: } \\
\text { Análisis de los resultados }\end{array}$ & Evaluación de la implementación \\
\hline
\end{tabular}

Fuente: elaboración propia.

\section{Bibliografía}

Aguilar, L. F. (1992). El Estudio de las Políticas Públicas. México D. F.: Porrúa.

Aguilar, L. F. (1992). La Hechura de las Políticas Públicas. México D. F. Porrúa

Alemán, C. y trinidad, A. (2006). Servicios sociales. planificación y evaluación. Navarra: Thomson-Cititas.

Angulo, J. F.; Contreras, J. y Santos, M. A. (1991). «Evaluación educativa y participación democrática». Cuadernos de Pedagogía, 195.

Bazaga, I. (1999). «El pensamiento estratégico en el ámbito público», en R. BAÑón. La nueva Administración Pública. Madrid: Alianza.

Beltran, M. (1987). «El Policy Analysis como instrumento de valoración de la acción pública». Revista de Estudios Políticos, 56.

Braybrooke, D. y Lindblom, Ch. E. (1963). A Strategy of Decision. Free Press.

Bryman, A. (1988). "Quality and Quality in Social Research». Contemporary Social Research Series, 18,

Brytting, T. (1991). Organizing in the small growing firm: A grounded theory approach. The Economic Research Institute.

Cahill, M. (1994). The New Social Policy. Blackwell. 
Carrero Planes, V. (1999). Análisis cualitativo de datos: aplicación de la teoría fundamentada ( "Grounded Theory») en el ámbito de la innovación organizacional. Castellón: Universidad Jaime I.

Clark, B. (1983). The higher education system. Academic Organization in Cross national perspective. Berkeley: University of California Press.

Cook, T. D. y Reichardt, C. S. (1986). Métodos cualitativos y cuantitativos en investigación evaluativa. Madrid: Morata.

Corvin, J. y Strauss, A. L. (1998). Basics of qualitative research: techniques and procedures for developing Grounded Theory. Thousand Oaks, CA: Sage publications.

Creswell, J. W. (1997). Qualitative Inquiry and Research Design. Choosing Among Five Traditions. Thousand Oaks, CA: Sage Publications.

Свомвасн, L. J. (1981). Toward reform of programmes evaluations. San Francisco: Jossey-Bass.

Dente, B. (1989). Politiche Pubbliche e Pubblica Administrazione. Maggioli, Rimini: Edizioni Scientifiche Italiane

Días Gomez, C. (1999). «Los métodos en la evaluación de los programas del objetivo 5b». Ponencia de las Jornadas sobre la Evaluación de los Programas de Desarrollo del Medio Rural. Pamplona.

Dror, Y. (1964). «Muddling Through, science or inertia?». Public Administration Review, 24.Traducción al castellano (1992). «Salir del paso, ¿ciencia o inercia?», en L. F. Aguilar (ed.). La Hechura de las Políticas. México D. F.: Porrúa..

Dye, TH. R. (1992). Understanding Public Policy. Prentice Hall. (7. a ed.).

Etzioni, A. (1967). «Mixed-Scanning. A third Approach to Decision Making». Public Administration, 27. Traducción al castellano (1992). «La exploración combinada. un tercer enfoque de la toma de decisiones», en L. F. Aguilar (ed.). La Hechura de las Políticas. México D. F.: Porrúa.

Fernández Ballesteros, R. (1996). Evaluación de programas sociales. Madrid: Síntesis.

Fischer, F. y Forester, J. (1993). The argumentative turn in Policy Analysis and Planning. New Haven: Yale University Press.

Gillroy, J. M. y Wade, M.(eds.) (1992). The Moral Dimensions of Public Policy Choice. University of Pittsburgh Press.

Glaser, B. (1992). Basic of Grounded Theory Analysis. Emergence vs. Forcing. Mill Valley, CA: Sociology Press.

Glaser, B. G. y Strauss, A. L. (1965). Awareness of Dying. Chicago: Aldine Publishing.

Glaser, B. y Strauss, A. (1967). The discovery of grounded theory: strategies for qualitative research. Nueva York: Aldine publishing. 
Glaser, B. (1992). Basic of Grounded Theory Analysis. Emergence vs. Forcing. Mill Valley, CA: Sociology Press.

Glaser, B. (1978). Theoretical sensitivity. Advances in the Methodology of Grounded Theory. Mill Valley, CA: Sociology Press.

Glaser, B. (2001). The Grounded Theory Perspective I. Conceptualization contrasted with description. Mill Valley, CA: Sociology Press.

Glaser, B. (2002). The Grounded Theory Perspective II. Description's remodelling of Grounded Theory Methodology. Mill Valley, CA: Sociology Press.

Heclo, H. H. (1972). «Review Article. Policy Analysis». British Journal of Political Science, 2.

Hill, M. y Bramley, G. (1990). Analysing Social Policy. Oxford: Basil Blackwell.

Hogwood, B. y Gunn, L. (1984). Policy analysis for the Real World. Oxford: Oxford University Press.

House, E. R. (1994). Evaluación, ética y poder. Madrid: Morata.

Kelly, M+y Maynard-Moody, S. (1993). «Policy Analysis in the Post-Positivist Era»* Public Administration Review, 53 (2).

Kogan, M. (1988). «Academic and administrative interface», en M. Henkel (ed.). Changing relationships between higher education and the state. Londres: Jessica Kingsley Pub.

Kuvale, S. (1996). Interviews. An Introduction to Qualitative Research Interviewing. Thousand Oaks: Sage Publications.

Lasswell, H. D. y Kaplan, M. (1950). Power and Society. New Heaven: Yale University Press.

Lasswell, H. D. (1951). «The Policy Orientation», en D. Lerner y H. D. Lasswell (eds.). The Policy Sciences: Stanford University Press.

Lindblom, Ch. E. (1959). «The Science of Muddling Through». Public Administration Review, 19. Traducción al castellano (1992). «La Ciencia de salir del paso», en L. F. Aguilar, (ed.). La Hechura de las Políticas. México D. F. Porrúa.

Lindblom, Ch. E. (1979). «Still Muddling, Not Yet Through». Public Administration Review, 39. Traducción al castellano (1992). «Todavía tratando de salir del paso», en L. F. Aguilar, (ed.), La Hechura de las Politicas. México D. F.: Porrúa.

Majone, G. (1989). Evidence, Argument and Persuasion in the Policy Process. Yale University Press. Primera edición en castellano (1997). Evidencia, Argumentación y Persuasión en la Formulación de Políticas. México: Fondo de Cultura Económica.

Manheim, J. B. y Rich, R. C. (1988). Análisis político empírico. Métodos de Investigación en Ciencia Política. Madrid: Alianza Editorial. 
Mcdonald, R.y Roe, E. (1991). «Evaluación de los departamentos», en M. De MiGUEL. La evaluación de las instituciones universitarias. Madrid: Consejo de Universidades.

Mcrae, Jr. D. (1980). «Concepts and Methods of Policy Analysis». Policy Studies Review Annual, 4.

Mcrae, Jr. D. (1981). «Valuative Problems of Public Policy Analysis», en J. P. CreCine (ed.). Research in Public Policy Analysis and Management, 1.

Miles, M. B. y Huberman, A. M. (1994). Qualitative data analysis. an expanded sourcebook. Newbury Park: Sage.

Nagel, S. (1980). The Policy-Studies Handbook. Lexington: Lexington Books.

Padagett, D. K. (1998). Qualitative Methods in Social Work Research. Challenges and Rewards. Thousand Oaks: Sage Publications.

Parlett, M. R. y Hamilton, D. (1976). «Evaluation in illumination. A new approach to the study of innovative programmes», en D. Hamilton et alii (eds.). Beyond the numbers game. Londres: MacMillan Education.

Pasquino, G. (comp.) (1988). Manual de Ciencia Política. Madrid: Alianza Editorial.

Patтon, M. (1990). Utilization-focused evaluation. Beverly Hills/Londres: Sage Publications.

Pérez Sánchez, M. (1997). Formación y Empleo en España. Análisis y Evaluación de la Politica de Formación Ocupacional. Granada: Universidad de Granada.

Pérez Sánchez, M. (1999). «El Análisis de las Políticas Públicas». Documentos de trabajo, n+ ${ }^{\circ}$ 14. Granada: Universidad de Granada.

Pérez Sánchez, M. y Trinidad, A. (2000). «Evaluación Institucional de la Facultad de CC. PP. y Sociología de la Universidad de Granada». Revista de Educación, 323.

Pérez Sánchez, M. (2000). «La calidad en la nueva gestión pública», en A. TriniDAD. Evaluación y Calidad en las Organizaciones Públicas. Madrid: INAP.

Pérez Sánchez, M. (ed.) (2005). Análisis de Politicas Públicas. Granada: Universidad de Granada.

Quade, E. S. (1989). Análisis de formación de decisiones politicas. Madrid: Instituto de Estudios Fiscales. Primera edición (1975). Analysis for public decisions. Elsevier Science Publishing.

Rippey, R.M. (1973). Studies in Transactional Evaluation. Berkeley, Calif.: McCutchan Publishing Corporation.

Rose, R. (1984). «Comparative Policy Analysis. The Programme Approach». Studies in Public Policy, 138.

Ruiz Olabúenaga, J. (1996). Metodología de la investigación cualitativa. Bilbao: Universidad de Deusto. 
Santos, M. A. (1990). Hacer visible lo cotidiano. Madrid: Akal.

Schrader, H. (1999). «El desarrollo rural y la evaluación de programas». Ponencia presentada en las Jornadas sobre la Evaluación de los Programas de Desarrollo del Medio Rural. Pamplona.

Scriven, M. S. (1989). «Evaluation bias and its control». Ocassional Paper Series, n. ${ }^{\circ}$ 4. Universidad de Western Michigan, Evaluation Center.

Simon, H. A. (1945). Administrative Behaviour. Nueva York: Free Press, Primera edición en castellano (1963). El comportamiento Administrativo. Madrid: Aguilar.

Simon, H. A. (1957). Models of Man. New York: John Wiley and Sons, Inc.

Simon, H. A. (1960). The new Science of Management Decision. Englewood Cliffs: Hall. Traducción al castellano (1977). La nueva Ciencia de la Decisión Gerencial. Buenos Aires: El Ateneo.

Simon, H. A. (1982), Reason in Human Affaire. Oxford: Blackwell.

Simons, H. (1999). Evaluación democrática de instituciones escolares. Madrid: Morata.

Soriano, R. M. (2004). El asentamiento de la mujer marroqui en el poniente almeriense. Madrid: CES

Stake, R. E. (1975). «Program evaluation, particularly responsive evaluation». Occasional Paper Series, 5.

Stufflebeam, D. L. y Shinkfield, A. J. (1987). Evaluación sistemática. Guía teórica y práctica. Madrid: Paidós-MEC.

Subirats, J. (1992). «Modelos de Política Social», en L. Moreno y M. Pérez YrueLA (comps.). Política Social y Estado de Bienestar. Madrid: Ministerio de Asuntos Sociales.

Subirats, J. (1988). «Notas acerca del Estado, la administración y las políticas públicas». Revista de Estudios Políticos, 59.

Subirats, J. (1989). Análisis de políticas públicas y eficacia de la Administración. Madrid: MAP.

Subirats, J. (2008). «En tiempos de cambio, evaluar», en VV. AA. El empleo en su contexto económico y social. Sevilla: Fundación Andaluza de Fondo de Formación y Empleo.

Sullivan, M. (1992). The Politics of Social Policy. Harvester Wheatsheaf.

Thoenig, J. C. (1985). «Lanalyse des Politiques Publiques». Traité de Science Politique, 4.

Torgerson, D. (1986). «Between Knowledge and Politics: three Faces of Policy Analysis». Policy Sciences, 19.

Trinidad Requena, A. (2007). La evaluación de la intervención pública. el caso de los programas sociales. Madrid: Sistema. 
Trinidad, A.; Carrero, V.y Soriano, R. M. (2005). Teoría Fundamentada «Grounded Theory»: la construcción de la teoría a través del análisis interpretacional. Cuaderno Metodológico, 35.

Trinidad, A. (2003). «La evaluación del Plan Nacional de Evaluación y Calidad Universitaria desde la Grounded Theory». Papers, 70.

Trinidad, A. (coord.) (2001). Evaluación y calidad en las organizaciones públicas. Madrid: Instituto de Administraciones Públicas.

Trinidad, A. y Pérez Sánchez, M. (1998). «Evaluación de Programas de Intervención Social». Revista del Ministerio de Trabajo y Asuntos Sociales, 10.

Trinidad, A. (1995). La evaluación de instituciones educativas. El análisis práctico de la Facultad de CC. Políticas y Sociología de la Universidad de Granada. Granada: Servicio de Publicaciones de la Universidad de Granada.

Valles, M. (1999). Técnicas cualitativas de investigación social. Reflexión metodológica y práctica profesional. Madrid: Síntesis.

Weitzman, E. A. y Miles, M. B. (1995). Computer programs for qualitative data analysis. London: Sage.

Weiss, C. (1977). Using Social research in public policy making. Lexington: D. C. Heath.

Wildavskx, A. (1980). Speaking Truth to Power. The Art and Craft of Policy Analysis. Boston: Little Brown.

Wilford, R. y Miller, R. E. (1998). Women, ethnicity and nationalism. The Politics of Transition. Londres: Routledge Sociology.

Wolcotт, H. F. (1994). «Posturing in Qualitative Inquiry», en M. D. Lecompte; W. L. Millroy y J. Preisle (eds.). The Handbook of Qualitative Research in Education. San Diego: Academic Press

Wolcotт, H. F. (1994). Transforming Qualitative Data. Description, Analysis and Interpretation. Thousand Oaks: Sage Publications.

Vidich, A. J. y Lyman, S. M. (1994). «Qualitative Methods. Their History in Sociology and Anthropology», en N.K. Denzin y Y. S. Lincoln (eds.). Handbook of Qualitative Research. Thousand Oaks: Sage Publications. 